\title{
MESTRADOS PROFISSIONAIS EM REDE: CONTRIBUIÇÕES E DESAFIOS PARA A FORMAÇÃO DOCENTE
}

\author{
Cecilia Rosa Lacerda (UECE)* \\ https://orcid.org/0000-0002-6798-4193 \\ Marli Eliza Andre (PUC/SP)** \\ https://orcid.org/0000-0002-0942-4008
}

\section{RESUMO}

Este texto é resultado de pesquisa que teve como objetivo analisar as contribuições e desafios dos Mestrados Profissionais em Rede no que se refere à formação docente, considerando o olhar dos coordenadores dos cursos. A abordagem metodológica foi qualitativa, tendo como procedimentos de coleta de dados a análise documental e entrevistas semiestruturadas, utilizando o skype e WhatsApp como recursos de comunicação. 0 aporte teórico compreendeu os estudos de Garcia (1999), Kincheloe (1997), Nóvoa (2017a) e Zeichner (1993, 2010), que tratam do conceito de desenvolvimento profissional, e a contextualização dos cursos de mestrados profissionais no Brasil foi tecida a partir das contribuições de Moreira (2004) e de Rezende e Ostermann (2015). A análise dos dados nos permitiu discutir três pontos: objetivos e identidade do mestrado; desafios vivenciados pelos gestores; e as contribuições para a formação do professor da educação básica. Os resultados apontaram que o mestrado profissional, em um contexto desafiador, exprime-se como importante dispositivo para a melhoria da formação e aprendizagem docente.

Palavras-chave: Mestrados profissionais em rede. Formação de professores. Aprendizagem docente.

\section{ABSTRACT}

\section{PROFESSIONAL MASTERS IN CHAIN: CONTRIBUTIONS AND CHALLENGES FOR TEACHER TRAINING}

This text is a result of research that aimed at analyzing the contributions and challenges of the Masters in chain in the teacher training in the view of the coordinators of the courses. The methodological approach was qualitative, having as procedures the bibliographic research and semi-structured interviews, using skype and WhatsApp as communication resources. The theoretical support

Pós-doutorado em Formação de Formadores pela Pontifícia Universidade Católica de São Paulo (PUC/SP). Professora Adjunta da Universidade Estadual do Ceará (UECE). E-mail: cecilia.lacerda@uece.br

** Doutora em Psicologia da Educação pela University of Illinois. Professora do programa de estudos pós-graduados em educação: psicologia da educação da Pontifícia Universidade Católica de São Paulo (PUC/SP). E-mail: marli.andre@gmail.com 
included the studies by Zeichner (1993, 2010), Garcia (1999), Nóvoa (2017a) and Kincheloe (1997), which deal with the concept of professional development and the contextualization of professional master's courses in Brazil it was composed by contributions from Moreira (2004), and Rezende and Ostermann (2015). The analysis of the data allowed us to discuss three points: objectives and identity of the master; challenges experienced by managers; and the contributions to the formation of the teacher of basic education. The results pointed out that the professional master's degree in a challenging context expresses itself as an important device for the improvement of teacher training and learning.

Keywords: Professional Master in Chain. Teacher training. Teaching learning.

\section{RESUMEN}

\section{MASTERS PROFESIONALES EN RED: CONTRIBUCIONES Y DESAFÍOS PARA LA FORMACIÓN DOCENTE}

Este texto resulta de una investigación que tuvo como objetivo analizar las contribuciones y los desafíos de los Masters Profesionales en Red con respecto a la formación docente, teniendo en cuenta la opinión de los coordinadores de los cursos. El enfoque metodológico fue cualitativo, teniendo como procedimientos de recolección de datos el análisis de documentos y entrevistas semiestructuradas, utilizando skype y WhatsApp como recursos de comunicación. El incremento teórico incluyó los estudios de Zeichner (1993, 2010), García (1999), Nóvoa (2017a) y Kincheloe (1997), que abordan el concepto de desarrollo profesional y la contextualización de los cursos de maestrías profesionales en Brasil, fue tecida a partir de las contribuciones de Moreira (2004) y Rezende y Ostermann (2015). El análisis de datos nos permitió discutir tres puntos: objetivos e identidad de la maestría; desafíos experimentados por los gestores; y las contribuciones a la formación del professor de educación básica. Los resultados mostraron que la maestría profesional, en un contexto desafiante, se expresa como un importante dispositivo para mejorar la formación y el aprendizaje docente.

Palabras clave: Masters profesionales en red. Formación de profesores. Aprendizaje docente.

\section{Introdução}

Os cursos de Mestrado Profissional no Brasil surgiram sob o compromisso de melhorar a qualidade da formação dos professores da educação básica pública, com o foco na articulação teoria-prática e na discussão e reflexão de situações vivenciadas pelos professores, por meio de práticas de intervenção, mobilizando pesquisa, formação e ensino.

Neste âmbito, a Portaria no 17/2009 traz a definição desses mestrados como modalidade stricto sensu, possibilitando ao egresso: a capa- citação de pessoal para a prática profissional por meio da incorporação do método científico, habilitando-o para atuar em atividades técnico-científicas e de inovação; a aplicação do conhecimento embasado no rigor metodológico e nos fundamentos científicos; e a incorporação e atualização dos avanços da ciência e das tecnologias e sua aplicação (BRASIL, 2009).

Diante disso, resolvemos empreender pesquisa a fim de compreender melhor as contribuições e os desafios que os Mestrados 
Profissionais têm enfrentado na formação docente. $^{1}$

Este texto tem a intenção de socializar os resultados de pesquisa sobre os Mestrados Profissionais em Rede no Brasil. Para tal, o texto foi organizado em quatro seções: a primeira, expressa os caminhos metodológicos adotados na pesquisa, detalhando os procedimentos de coleta e análise dos dados; a segunda seção apresenta os pressupostos teóricos; a terceira contextualiza o mestrado profissional em rede no Brasil; e a quarta analisa os dados da investigação, tendo como eixos: os objetivos e a identidade do curso, as dificuldades e desafios vivenciados pelos gestores e as contribuições desse programa para a formação dos professores da educação básica. Nas conclusões, são apresentadas evidências instigadoras do debate e indicadas novas pesquisas no campo.

\section{Percurso metodológico}

A pesquisa ancorou-se na abordagem qualitativa, já que se buscou compreender e analisar os significados atribuídos pelos coordenadores dos cursos ao processo de desenvolvimento e à implementação do Mestrado Profissional em Rede.

O caminho consistiu, no primeiro momento, em mapear os cursos de mestrado profissional no Brasil e identificar os coordenadores dos programas, considerando dados da Plataforma Sucupira e sites das instituições do ensino superior que desenvolvem o mestrado em rede. Em seguida, foram enviados 11 convites, por meio do correio eletrônico, para os coordenadores dos cursos do Mestrado Profissional, convidando-os para participar da pesquisa, levando-se em consideração o fato de que fossem contemplados cursos de todas as regiões do Brasil.

É importante destacar que tais cursos abarcavam diversas áreas: Ciências Ambientais, Educação Física, Matemática, Física, Biologia,

1 Pesquisa de conclusão de estágio pós-doutoral realizada na PUC/SP no Programa Mestrado Profissional - Educação: Formação de Formadores.
Química, Letras, História, Filosofia, Artes e Educação Tecnológica e Profissional. Oito coordenadores de curso aceitaram participar da pesquisa e colaboraram por meio da realização de entrevistas semiestruturadas, utilizando skipe e whatsapp como instrumento de comunicação.

Os dados obtidos por meio das entrevistas favoreceram o entendimento dos itens expressos no roteiro, tais como: características do curso; dificuldades e desafios no desenvolvimento do Programa; implicações na educação básica; e, por fim, as contribuições do Mestrado para a formação do professor.

Um dos pontos positivos na entrevista foi conhecer os coordenadores dos cursos no Brasil e a "captação imediata e corrente da informação desejada" (LÜDKE; ANDRÉ, 1986, p. 34). No decorrer do diálogo, buscamos entender o contexto e solicitar esclarecimentos sobre as experiências vivenciadas nas instituições.

$\mathrm{Na}$ análise dos dados, utilizamos a abordagem denominada Análise de Prosa (ANDRÉ, 1983), que nos orienta a investigar o significado dos dados qualitativos, considerando as mensagens intencionais e não-intencionais, explícitas ou implícitas. A autora nos adverte para ter atenção com "[...] a variedade de mensagens que podem estar presentes numa simples fração do discurso e a impossibilidade de se apreender a totalidade do objeto sem investigar as diferentes concepções, pressupostos, implicações envolvidas [...]" (ANDRÉ, 1983, p. 67). Na pesquisa, foram "muitos dedos de prosa" com os coordenadores dos mestrados, o que exigiu atenção especial para a interpretação das falas que permearam as entrevistas, tendo como fio condutor as imbricações dos cursos na formação do professor da educação básica.

Para isso, as etapas que orientaram esse momento do estudo foram: escuta sensível das "prosas" dos coordenadores; leituras das transcriç̧ões das entrevistas; interpretação das questões abordadas, tendo como referência as características do mestrado, os desafios do curso, a importância e as contribuições para 
a formação docente e as implicações desse mestrado na educação básica.

\section{Discussão dos conceitos}

Para entender e analisar o fenômeno investigado foi necessário aprofundar o estudo de concepções como formação docente e desenvolvimento profissional, mestrado profissional, dentre outras. Desse modo, os fundamentos teóricos foram pensados com base nos referenciais de Garcia (1999), Kincheloe (1997), Kuenzer (1999), Nóvoa (2017a), Moreira (2004), Rezende e Ostermann (2015), Zeichner (1993, 2010).

Na literatura acadêmica, identifica-se que a formação docente é concebida como "[...] matriz de crenças e pressupostos acerca da natureza e propósitos da escola, do ensino, dos professores e da sua formação, que dão características específicas à formação de professores" (ZEICHNER, 1993, p. 3).

A concepção tradicional de formação é alicerçada na racionalidade instrumental, reduzindo-se a aplicação técnica dos saberes no cotidiano da atividade profissional. Caracteriza-se pela aprendizagem das competências de um ensino eficaz, centrado no professor como transmissor do conteúdo e pelo controle das tarefas realizadas pelos estudantes (GARCIA, 1999).

A concepção que defendemos extrapola a dimensão da formação como algo individual e pontual, sendo ampliada para o conceito de "desenvolvimento profissional docente". Subjacente a essa concepção valoriza-se a relação dialógica entre os sujeitos do processo educativo e um movimento permanente de estudos e pesquisas sobre a prática docente, num processo contínuo de aprendizagem, para que assim possam ser ampliados os saberes teórico-práticos dos sujeitos da formação, conforme defende Garcia (1999).

Entendemos que a prática da reflexão no processo formativo provoca as aprendizagens docentes, que exigem sistematização e orga- nização, conforme recomenda Garcia (1999, p. 30) ao conceber a formação docente como

[...] processo sistemático e organizado mediante o qual os professores - em formação ou em exercício - se comprometem individual e coletivamente em um processo formativo que, de forma crítica e reflexiva, propicie a aquisição de conhecimentos, destrezas e habilidades que contribuam no desenvolvimento de sua competência profissional.

A prática reflexiva se concretiza na reconstrução dos saberes tecidos na escola, por meio de interação e discussão entre os pares. Para isso, atentamos para a importância das condições objetivas e subjetivas para essa prática, como: autonomia de pensamento, clima escolar positivo, cultura organizacional democrática, condições adequadas de trabalho.

A reflexão é um princípio fundamental do desenvolvimento profissional e este não pode ocorrer de forma prescritiva e pontual. A formação, que é parte do desenvolvimento profissional, impulsiona o que é denominado de "protagonismo docente", trazendo o professor para o debate da sua profissão com a valorização da formação que possibilite “ [...] a preparação de professores reflexivos, que assumam a responsabilidade do seu próprio desenvolvimento profissional e que participem como protagonistas na implementação das políticas educativas (NÓVOA, 2017a, p. 27).

Neste protagonismo docente, as ações colaborativas aparecem como alternativa de formação, no entanto é preciso lutar para que isso aconteça, pois em geral, "não há oportunidades, nem encorajamento suficiente para os professores atuarem em conjunto, para aprenderem uns com os outros e melhorarem sua qualificação como uma comunidade" (FURLAN; HARGREAVES, 2000, p. 15). Assim, defendese a ideia de que é preciso criar condições de aprendizagem docente, por meio de estratégias interativas que valorizem os saberes dos professores.

A aprendizagem docente se faz em longo prazo devido à complexidade da profissão, 
demandando do profissional o envolvimento em atividades que lhe são próprias. Mizukami (2013, p. 23) afirma que "[...] a docência é uma profissão complexa e, tal como as demais profissões, é aprendida. Os processos de aprender a ensinar, de aprender a ser professor e de se desenvolver profissionalmente são lentos [...]". Isso se dá no decorrer da trajetória pessoal e profissional do professor, antes mesmo de sua entrada na formação inicial, estendendo-se pela vida, uma formação permanente, em variados espaços, envolvendo dimensões pessoais, institucionais e culturais (FIORENTINI, 2008).

As vivências dos professores que mais contribuem para a sua formação são aquelas experienciadas no contexto escolar e que se dão de maneira colaborativa, na medida em que o desenvolvimento profissional é conceituado como processo de reconstrução da cultura escolar e de mudança (GARCIA, 1999). Essa visão de desenvolvimento profissional vai além da ideia de aquisição de destrezas, sendo caracterizada pela sua dimensão coletiva e dimensão crítica, como explicitado por Day (2001, p. 2021, grifo nosso):

[...] é o processo através do qual os professores, enquanto agentes de mudança, reveem, renovam e ampliam, individual ou coletivamente, o seu compromisso com os propósitos morais do ensino, adquirem e desenvolvem, de forma crítica, juntamente com as crianças, jovens e colegas, o conhecimento, as destrezas e a inteligência emocional, essenciais para uma reflexão, planificação e prática profissionais eficazes, em cada uma das fases das suas vidas profissionais.

Entender o desenvolvimento profissional do professor implica pensar sobre como articular o fato de que a formação se dá ao longo da vida, que a escola deve ser a referência central da formação e que as experiências tecidas na trajetória pessoal e profissional são importantes, de forma a considerar os diversos contextos formativos.

A formação fundamentada na experiência, englobando variados espaços, não se limita à supervalorização do cotidiano em detrimento da dimensão teórico-prática, nem se restringe à realização de eventos pontuais. Nesse sentido, Nóvoa (2017a, p. 25) critica a formação como promoção de cursos:

A formação não se constrói por acumulação (de cursos, de conhecimentos ou de técnicas), mas sim através de um trabalho de reflexividade crítica sobre as práticas e de (re)construção permanente de uma identidade pessoal. Por isso é tão importante investir a pessoa e dar estatuto ao saber da experiência.

Os cursos, em geral, se mantêm distantes da realidade dos participantes, tratam de temas que dicotomizam saberes teóricos e pedagógicos, são desconexos das demandas formativas dos professores, reduzem esses programas de formação a palestras, com o objetivo restrito de atualização e treinamento. Apresentam práticas e modelos genéricos de resolução dos problemas pedagógicos, não promovendo, assim, um movimento de reflexão da prática e sobre a prática.

Contrariamente, ao assumir uma postura de reflexão sobre seu fazer, o professor pode se tornar um "eterno aprendiz", que o leve a gerar expectativas de aprendizagens docentes, que podem se constituir em "demandas formativas", com suporte nos seus dilemas e desafios pedagógicos. Demandas são entendidas como “[...] resultantes do confronto entre expectativas, desejos e aspirações, por um lado e, por outro, as dificuldades e problemas sentidos no quotidiano profissional" (RODRIGUES, 1991, p. 476).

As necessidades de formação no contexto do desenvolvimento profissional docente podem ser consideradas uma forma de pensar os programas em uma dimensão macro, favorecendo indicativos para deliberação de quais conteúdos e estratégias devam ser utilizados na formação. Também consideram que o processo formativo ocorre em um movimento, na medida em que os anseios dos professores podem evoluir, modificar-se. Os contextos podem ser alterados e, consequentemente, mudam os temas e estratégias planejados para a formação. 
Rodrigues (2006, p. 121) afirma que "as necessidades de formação são o ponto de partida e o ponto de chegada de uma política de formação que se pode designar contínua".

\section{0 mestrado profissional no brasil}

O mestrado profissional no Brasil foi instituído em 2009, por meio da Portaria Normativa nº 7/2009, inserido na pós-graduação stricto sensu, igualando a titulação ao Mestrado Acadêmico (BRASIL, 2009). Posteriormente, a Portaria Normativa $\mathrm{n}-17$, do mesmo ano, definiu os objetivos:

I- capacitar profissionais qualificados para o exercício da prática profissional avançada e transformadora de procedimentos, visando atender demandas sociais, organizacionais ou profissionais e do mercado de trabalho; II - transferir conhecimento para a sociedade, atendendo demandas específicas e de arranjos produtivos com vistas ao desenvolvimento nacional, regional ou local; III - promover a articulação integrada da formação profissional com entidades demandantes de naturezas diversas, visando melhorar a eficácia e a eficiência das organizações públicas e privadas por meio da solução de problemas e geração e aplicação de processos de inovação apropriados; IV - contribuir para agregar competitividade e aumentar a produtividade em empresas, organizações públicas e privadas. (BRASIL, 2009).

Pode-se ressaltar algumas premissas desse mestrado, tais como: a capacitação profissional e sua relação com a prática, atendendo as necessidades do mundo do trabalho; a imbricação dos conhecimentos produzidos com o desenvolvimento social; a importância da integração da formação profissional com as demandas sociais, visando à eficácia e à eficiência das instituições; e o aumento da competitividade e produtividade das empresas.

Para os professores da educação básica, apresentam-se os mestrados profissionais em rede nacional com o objetivo de "[...] fomentar a manutenção e o desenvolvimento dos progra- mas de pós-graduação nesta modalidade para qualificação de docentes do ensino básico das redes públicas. [...]" (BRASIL, 2017).

Com a criação dessa modalidade de mestrado profissional, houve uma expansão dos cursos no Brasil. Iniciou-se com o Mestrado profissional em Matemática (PROFMAT), depois ampliou-se para os cursos do Ensino das Ciências Ambientais, Ensino de Ciências, Ensino de Física, Educação Profissional, Letras, Artes, Ensino de História, Ensino de Biologia, Química, Filosofia, Sociologia, e Educação Física (COORDENAÇÃO DE APERFEIÇOAMENTO DE PESSOAL DE NÍVEL SUPERIOR, 2017).

Desenvolver pesquisas articuladas à prática docente torna-se o ponto central desses mestrados e a efetivação de aprendizagem para estudantes-professores e também para a universidade, tornando-se um instrumento de desenvolvimento profissional dos sujeitos envolvidos. Os sujeitos da instituição de ensino superior aprendem com os saberes dos professores no cotidiano da escola, ajudando-os na integração de teoria e prática, e os estudantes -professores aprendem a direcionar a prática com o olhar de investigadores.

A importância desses mestrados se destaca quando são organizados para os professores do ensino fundamental e médio, trabalhando as competências que lhes são próprias, como: atuar nos processos de formação de grupos de trabalho; ser capaz de desenvolver e implementar o currículo; coordenar e orientar grupos nos diversos processos de avaliação do sistema escolar (MOREIRA, 2004).

\section{Dedos de prosa: análise das conversas com os coordenadores}

Apresentamos, a seguir, os resultados das "prosas" efetivadas com os coordenadores de alguns cursos dos mestrados profissionais em rede no Brasil, focando suas imbricações no desenvolvimento profissional docente. 
Revelamos, inicialmente, o que os coordenadores dos cursos de mestrado profissional pensam sobre os objetivos e identidade dos cursos. Prosseguimos apresentando as dificuldades e desafios vivenciados pelos sujeitos da pesquisa e finalizamos apontando as contribuições desse programa para a formação dos professores da educação básica.

Em geral, os coordenadores ${ }^{2}$ revelam ter clareza dos objetivos dos programas, conforme expressam a seguir:

Nosso objetivo é a formação dos profissionais que trabalham na Educação Profissional e Tecnológica. Seja no trabalho docente, no sentido estrito da palavra, ou em ações de gestão, de organização que favorecem a efetivação da docência. Então a expectativa é que a gente realmente possa contribuir com isso. 0 curso traz na matriz conceitos de cidadania, da transformação de um olhar mais crítico da relação trabalho e educação. (C1).

Os nossos alunos são todos professores, claro que [...] com alguns anos de experiência [...], que uma das exigências é que seja professor efetivo, que trabalhe numa sala de aula. No caso da História, a nossa preocupação é possibilitar ao aluno uma reflexão teórico-metodológica sobre o ensino da disciplina, oferecendo a eles disciplinas variadas que possibilitem isso. (C3).

0 objetivo é que, a partir da realidade profissional, ele produza uma reflexão, mas também o que nós chamamos de 'Produto Educacional', que pode ser um instrumento pedagógico, um recurso didático, logo, com a proposta de oficina, de peça de teatro, de algo que tenha alguma relação com o trabalho que ele realiza em sala de aula. (C3).

0 projeto do curso é a formação de professores da Educação Básica, das Escolas Públicas, então para ingressar precisa, necessariamente, fazer parte dos quadros efetivos da Escola Pública. (C5).

Notamos, nesses depoimentos, que os coordenadores delineiam a unidade da proposta do mestrado, tendo como fio condutor a formação de professores para a educação básica, bem

2 Adotamos para identificação dos coordenadores participantes da pesquisa os códigos $\mathrm{C} 1, \mathrm{C} 2, \mathrm{C} 3, \mathrm{C} 4, \mathrm{C} 5$, C6, C7 e C8. como o estudante-professor como sujeito desse programa, apontando a dimensão reflexiva como foco principal no processo de desenvolvimento profissional. Assim, “[...] o eixo fundamental do currículo de formação do professor é o desenvolvimento da capacidade de refletir sobre a própria prática docente, com o objetivo de aprender a interpretar, compreender e refletir sobre a realidade social e a docência" (IMBERNÓN, 2006, p. 39).

Nessa direção de efetivar a reflexão da própria prática, é trazida a emergência do protagonismo docente:

O curso é pautado na construção do conhecimento, e não na sua mera reprodução. A proposta é colocar o aluno (professor) como protagonista do processo de ensino-aprendizagem e que os conhecimentos construídos nas aulas do Mestrado, conhecimentos esses que são aprofundados, possam ser levados para a sala de aula, local de trabalho do professor; e que sejam desenvolvidas estratégias de abordagem desses temas, para que possam ser trabalhados na educação básica de uma forma adequada. (C6).

[...] tem que ter a puxada, fisgada para o ensino... se você vir o nome das disciplinas... 'Texto e Ensino', 'Gramática e Variação do Ensino,' 'Ensino do Texto', 'Literatura e Ensino', então temos a tentativa de aliar a produção teórica aplicada ao que se faz realmente em sala de aula, o que se pode fazer. Para isso é preciso envolver o estudante nas atividades elaboradas com o grupo. (C5).

A ação de se tornar o ator principal do seu desenvolvimento profissional é, também, expressa nas diretrizes curriculares nacionais para a formação inicial e continuada dos profissionais do magistério da educação básica, quando indica que devem constar: o respeito ao protagonismo do professor e o espaço-tempo que lhe permita refletir criticamente e aperfeiçoar sua prática (DOURADO, 2015).

A formação definida no Mestrado Profissional em Matemática volta-se para os aspectos conceituais do conteúdo da área específica, conforme o depoimento de um coordenador:

A ideia inicial era de um curso para formação para professores da educação básica, de buscar aprimoramento profissional desses professores 
com ênfase no aprofundamento do conteúdo matemático, conteúdo matemático que é relevante para a atuação desses professores na educação básica. E ainda, [...] a gente sempre dá ênfase a disciplinas que aprimorem os conteúdos, que eles têm uma deficiência grande, que aprimorem os conteúdos relacionados com a educação básica e sempre a gente, nós, como professores, procuramos desenvolver estratégias para melhor expor esses conteúdos para os alunos da educação básica, a gente sempre toma esse cuidado, mas, assim, disciplina específica pedagógica não tem. (C7).

Evidenciamos que o objeto do PROFMAT são os conteúdos específicos, direcionados à dimensão matemática, aproximando-se da afirmação de que basta o profissional conhecer o conteúdo - de uma perspectiva da Matemática de teor acadêmico - para desempenhar a função de professor da educação básica (CALDATTO, 2015).

Além dessa evidência, os coordenadores dos Programas de Mestrados estudados elucidam a diferença entre o mestrado profissional e o mestrado acadêmico quando fazem referências ao trabalho de conclusão do curso, tendo a intervenção na realidade escolar como característica principal que demarca sua especificidade:

[...] tem um objetivo diferente do acadêmico. 0 acadêmico tem uma característica essencial para o curso, que é a natureza do trabalho de conclusão. A conclusão precisa ser uma proposta de intervenção, então, pelo menos nas diretrizes gerais do PROFLETRAS nacional, todos os alunos fazem uma proposta de intervenção em sala de aula, então isso é uma primeira diferença. A outra diferença que a gente tenta fazer, mas ainda não conseguiu, é que os alunos, além de produzirem um relatório com cara de texto acadêmico, como produção final, eles vão fazer também um manual pedagógico, uma espécie de tentativa de colocar para um outro professor o que eles fizeram, com um viés mais pedagógico que propriamente descrição da pesquisa. (C4).

[...] pode fazer em um modelo de caráter pedagógico na área de artes, que efetivamente tenha sido aplicado na escola, então a dissertação pode ser esse projeto pedagógico, da análise e da execução, da avaliação desse projeto pedagógico artístico, desenvolvido dentro da escola, e uma modalidade que é um projeto de artes desenvolvido dentro da escola, planejado e desenvolvido dentro do espaço escolar. [...] a característica principal do curso é a formação desses professores, valorizando a atuação profissional deles efetivamente dentro da escola, [...] modelo que o mestrado acadêmico faz é de uma dissertação que é descrever um fenômeno e analisá-lo, claro, de um nível... nível, não, dentro de um critério de avaliação e expectativas que temos para um mestrado. (C5).

O mestrado profissional enfatiza estudos e técnicas diretamente voltadas ao desempenho da qualificação profissional de alto nível, oferecendo a mesma legitimidade do mestrado acadêmico, inclusive para o exercício da docência. Responde a uma necessidade definida de capacitação profissional de natureza diferente da propiciada pelo mestrado acadêmico, sendo o produto o resultado do curso. 0 programa acadêmico tem como característica a imersão na investigação, formando, a longo prazo, um pesquisador. Dito por André (2017, p. 832): "[...] as pesquisas acadêmicas têm (ou deveriam ter) um compromisso com a teoria, com o avanço teórico", e o mestrado profissional tem como objeto a formação profissional, efetivando a "pesquisa engajada que está voltada para a prática e seu aprimoramento".

Ainda no viés da práxis profissional, as intervenções se materializam no ensino, objeto dos mestrados investigados, por meio de elaboração de projetos nas escolas e sua aplicação na sala de aula do professor, como esboçam os coordenadores:

Agente está tentando introduzir novas metodologias para eles, que são professores, empregarem em sala de aula no ensino básico. É até meio contraditório se nós não nos valermos desses recursos, dessas novas metodologias para tentar também fazer que eles possam aprender algo novo... A gente quer que eles implementem essas metodologias, que os alunos se interessem mais, aprendam mais. (C2).

[...] 0 curso tem a proposta de trabalhar com o ensino de Biologia, partir da metodologia científica. Trabalha um aspecto do conhecimento 
biológico, e eles (os alunos) precisam desenvolver uma aplicação em sala de aula de cada um dos temas. Então, a cada semestre eles escolhem um de cada conteúdo que foi trabalhado e precisam elaborar um projeto de aplicação, aplicar e apresentar resultados dessa aplicação, desse projeto na sua sala de aula. Todos os alunos do PROFBIO têm que estar em sala de aula, para poder fazer essa transposição do que eles estão desenvolvendo no próprio PROFBIO para a sala de aula deles [...]. (C8).

Observamos que as intervenções se desenvolvem com o objetivo de melhorar a prática docente, que implicaria a aprendizagem dos estudantes da educação básica, fazendo com que o professor reflita sobre os problemas que vivencia no cotidiano da escola e pense e elabore alternativas para melhoria da prática pedagógica. Há, nesse sentido, a premissa de que o espaço escolar é um espaço em que as questões que envolvem a dinâmica da instituição precisam ser discutidas coletivamente com os sujeitos, nos processos imbricados na sua própria prática.

No que se refere à identidade do curso, os sujeitos explicitam as propostas dos mestrados, sendo comum a ideia da centralidade no ensino e a definição do perfil dos estudantes-professores, destacando a formação em serviço do projeto do seu escopo. 0 ensino é mostrado como foco, apontando com clareza que não é um programa da área específica do conhecimento, mesmo que em alguns momentos tenha sido visualizado um viés conteudista:

Não é um mestrado em Física. É um mestrado profissional que se dirige para os profissionais que estão em sala de aula. Tem um público-alvo preferencialmente da rede pública, e pequena quantidade de vagas para a rede privada, mas condição sine qua non para fazer parte do Programa é estar em sala de aula, em efetivo exercício em sala de aula [...]. Tem o viés conteudístico. (C2).

Os mestrados em rede, para profissionais, são muitos diversos uns em relação aos outros, a natureza, a perspectiva pedagógica. É o que acompanho sobre o MNPEF - ensino de Física, O PROFMAT - Matemática, o PROFLETRAS, enfim, são todos muitos distintos ainda. 0 que têm em comum é o fato de o público-alvo são profissionais que atuam nas redes de ensino. 0 nosso objetivo é contribuir na qualificação do trabalho dos colegas das redes de ensino. (C3).

[...] nós não temos disciplinas de conteúdo no sentido de História do Brasil, História da América ou qualquer história, mas temos disciplinas sobre currículo, sobre a condição do professor, sobre metodologia da história. São disciplinas gerais que tentam pensar e fazer relação do trabalho, da nossa área de conhecimento, considerando de forma muito imediata ao ensino dessa disciplina na realidade escolar. Então o que ocorre é que o aluno que chega, até porque ele é um profissional em serviço, acaba a todo momento refletindo sobre seu próprio fazer, porque instigado a isso. $\mathrm{E}$ a partir da realidade que ele atua, vai ter que escolher um problema de pesquisa. Isso traz toda uma preocupação reflexiva que é muito interessante. (C3).

Verificamos, como foi expresso anteriormente, a práxis como categoria que define o curso, quando é valorizada a reflexão das experiências docentes, que se transformam em objeto de investigação. 0 problema de pesquisa nos mestrados profissionais em rede é construído nas inquietações originadas do cotidiano escolar.

Muitos foram os desafios delineados nas "prosas" com os gestores dos programas, sendo destacados cinco aspectos: a diferença de ensinar e pesquisar no mestrado acadêmico com o mestrado profissional; a dimensão das intervenções dos trabalhos finais; a melhoria da capacidade de reflexão pedagógica sobre o ensino e a inserção dos conteúdos da escola no currículo; a unidade dos programas em rede; e as implicações na educação básica.

0 primeiro aspecto refere-se à especificidade de ensinar no mestrado profissional, diferenciando-se do mestrado acadêmico, realidade esta vivenciada por professores dos programas:

A maior parte dos nossos docentes é originário de programas de mestrado e doutorado em educação e nós estamos numa nova linha de mestrado em ensino, então, fazer essa adequa- 
ção de percepção de concepção dos professores também está sendo um desafio interessante. [...] Na Capes, a área do ensino está na área interdisciplinar e não na área de educação. 0 foco é no ensino de alguma coisa, então, no nosso caso, é o ensino na educação profissional e tecnológica. Então, [...] de alguma forma, os professores precisam compreender que têm que pesquisar o ensino e o ensino ainda é novidade... Porque deve ser nas práticas de ensino, esses profissionais estão precisando se fortalecer nessa compreensão. (C1).

O fato de que nós professores, gestores do curso, não sabíamos o que era o mestrado profissional, todos nós somos originados de pós-graduações acadêmicas, produzimos teses e dissertações tradicionais. Digamos assim, no início nos assustava um pouco essa modalidade, que não necessariamente precisa ser uma dissertação, pode ser um produto. Ainda que exija uma parte teórica de fundamentação, para além disso, no caso dos mestrados em rede, as instituições não estão acostumadas com essa modalidade de funcionamento de pós-graduação. (C3).

Verificamos que o objeto pedagógico do curso é o ensino e que os professores tiveram experiências de pesquisas no campo dos saberes teóricos, distanciando-se das propostas de pesquisas dos mestrados profissionais, que necessariamente exigem investigações com intervenções nas práticas profissionais. Os docentes passam, pois, por um processo de adaptação e apropriação de novas formas de ensinar e pesquisar.

O segundo desafio volta-se para as intervenções dos trabalhos finais, como declara um coordenador: "[...] entendeu, ah e deixa eu te dizer uma coisa, outro problema, mas que não é do curso, mas que é da natureza da pesquisa, porque eu estou relacionando mais o meu grupo de pesquisa que ainda as intervenções são muito pontuais". (C4).

Observamos a preocupação em ampliar as intervenções, dando um caráter mais transformador, englobando não só uma prática de ensino, mas todo o trabalho pedagógico, de pensar o desenvolvimento profissional de forma macro e coletiva. Para isso, a pesquisa deve ser caracterizada por ações que possam interferir na realidade, visando, com o grupo, a modificar situações pedagógicas, passando, então, a ser um dispositivo de interferência, tendo como pressuposto mudança de concepção de aprendizagem e de ensino.

Melhorar a reflexão pedagógica sobre o ensino e inserir essa prática na matriz curricular do mestrado são pontos que envolvem os conteúdos da educação básica e configuram o terceiro desafio, na perspectiva dos coordenadores:

[...] aprimorar o conhecimento dos seus alunos sobre a ciência, no caso a disciplina que eles ministram, porque entendem os colegas que os problemas no ensino do professor é porque ele domina pouco a sua própria área de conhecimento. No caso da História, nós não pensamos assim, nós entendemos que o professor de História é um profissional habilitado, formado, que tem capacidade em razão de procurar eventualmente atualizações necessárias sobre o conhecimento de História [...] historiográfico específico, então no mestrado o nosso objetivo é capacitar, aumentar a capacidade de reflexão pedagógica sobre o ensino da disciplina. (C3).

[...] a organização curricular do PROFLETRAS é ainda por área teórica. 0 desafio é que esse programa ficasse mais condizente com as dimensões as quais o professor trabalha. Eu sou o professor, sou, por exemplo, da área da linguística textual, mas se fosse da leitura e ensino, seria leitura, e se quisesse trazer suporte da linguística textual para leitura, eu traria, se tiver uma perspectiva de um sujeito que trabalha leitura. (C4).

Percebe-se um entendimento de que os conhecimentos das áreas específicas precisam estar articulados com o conhecimento didático, quando o coordenador indica a reflexão pedagógica como necessária à prática de ensino. Nessa direção, devem ser dinamizados também, na elaboração da matriz curricular, os saberes da escola, conteúdos trabalhados na educação básica pelos estudantes-professores.

O quarto desafio apontado pelos coordenadores foi garantir a unidade dos mestrados em rede:

[...] os cursos estão vinculados às instituições, eles também estão inseridos numa rede, que é 
muito mais ampla, inclusive, isso demanda da coordenação nacional uma série de tarefas e responsabilidades de alguns colegas que têm a função de unificar, padronizar mais ou menos, dentro do possível, as rotinas, as características. Afinal de contas, somos um curso que funciona em mais de 20 instituições no país. (C3).

Por ser um mestrado em rede, a nossa universidade [...], de certa forma, precisamos seguir os cronogramas e as determinações. Acho que há uma diminuição da autonomia, isso pode dificultar, pois temos nossas especificidades, ao mesmo tempo que temos que nos adequar às determinações de um mestrado com muitas instituições envolvidas, tendo que estar encadeadas, necessitando de um ritmo cadenciado. Assim, considerando nossas particularidades e que o corpo discente é formado por professores que estão em atividade na sala de aula da educação básica, tendo que conciliar as exigências do estudo na pós-graduação e a sua prática profissional, isso pediria mais flexibilização e menos rigidez. (C6).

[...] ser um mestrado profissional em rede, a gente precisa ter muitas decisões e essas decisões acabam sendo centralizadas na coordenação nacional. Então a gente não tem, assim, muita autonomia pra decidir. Por exemplo, o foco que a gente quer dar para cada um dos tópicos ou os conteúdos propriamente ditos. Então é uma coisa que a gente precisa ficar esperando que esses tópicos sejam decididos. Há um fórum de discussão, onde os professores de cada tópico estão conversando para tentar chegar a um planejamento em comum e... Mas, assim, sempre tem críticas sobre o planejamento final, então o principal desafio é relacionado a essa estrutura mesmo da rede, que a gente gostaria de ter um pouco mais de autonomia pra isso; eles definem os conteúdos de cada tópico. (C8).

Nota-se que implementar programas de mestrado em rede não é tão fácil, principalmente por exigir uma cultura de colaboração no que se refere aos procedimentos, exigindo maior organização e uma unidade na concepção do curso. Nesse sentido, há aspectos que não podem ser confundidos, como uniformidade com unidade; heteronomia com autonomia; e a negação das realidades com a garantia das especificidades locais. Observa-se que essa ideia de rede está sendo construída paulatinamente, sendo necessário tempo para definir essa nova maneira de desenvolver formação docente na instância da pós-graduação, mudando os sentidos pré-estabelecidos na trajetória pessoal e profissional e indicando quebra de paradigmas.

0 último desafio, a efetivação do impacto na educação básica, é expresso nas falas a seguir:

O maior desafio do PROFMAT é exatamente esse, aperfeiçoar, a chegada de tudo o que os professores estão adquirindo desse aperfeiçoamento, fazer isso chegar na educação básica, aprimorar [...], otimizar essas aplicações na educação básica, fazer com que os trabalhos de conclusão de curso sejam mais voltados pra isso, entendeu? [...] uma pergunta recorrente nas avaliações era sempre essa: 'Como é que você faz isso chegar na educação básica?' Muita gente fez como minha aula, foi satisfatório e tal, mas alguns disseram pelo Brasil afora que sequer chegou a aplicar pra ver a viabilidade na educação [...] É romper essa barreira, novamente ressalto, tem chegado, mas pode ser melhorado muito, esse impacto na educação básica pode ser muito maior; tem impacto na formação de professores, a gente vê, a gente percebe esse... o nível de proficiência em matemática aumentando, não na velocidade que a gente gostaria, mas a gente percebe que tá aumentando, tá melhorando, mas eu acho que essa velocidade pode ser aumentada, o curso pode ser aperfeiçoado. (C7).

Mas o impacto maior inicial que a gente pode avaliar efetivamente é nos próprios estudantes do mestrado, dos desdobramentos no ensino básico. [...] Digamos assim, a espinha dorsal do mestrado é o produto educacional que o aluno desenvolve pra aplicar em sala de aula. [...] Dentro do espírito da filosofia do MNPF, a gente quer realmente fazer algo inovador, que mexa com as estruturas, diferente, que não caia na mesmice, do que já tá nos livros-textos... A gente tenta buscar novas formas de compreender os fenômenos, de compreender... claro, a gente não pode escapar das leis da natureza, da física, que já estão formuladas, mas a gente tenta fazer conexões, novas conexões entre esses fenômenos. Por exemplo, o que se passa no cotidiano dos alunos. Também tentar buscar um viés multidisciplinar que ajude na articulação; novas tecnologias têm sido positivas, a experiência positiva para eles enquanto formandos, foram alunos do mestrado e acredito que isso também seja transmitido para os alunos da rede básica. (C2). 
Falar da implicação do mestrado na educação básica remete ao objetivo do curso, que é a formação profissional do docente; em consequência, a melhoria da qualidade do ensino.

Em sintonia com essa formação e ressaltando essa intervenção na escola, destacam-se: a indicação do fortalecimento da base epistêmica ao relacionar educação superior e educação básica; o potencial de qualificação dos sistemas de ensino e outros ambientes profissionais; e a abordagem dada aos problemas educacionais como parte integrante do desenvolvimento profissional docente por meio de formação, pesquisa e desenvolvimento de produtos voltados para a prática pedagógica (FIALHO; HETKOWSKI, 2017).

0 viés epistemológico se consubstancia na mudança de paradigma de como se aprende e ensina na universidade e na escola, em que ambos os polos são concebidos como lócus de formação docente e o conhecimento construído no processo de mobilização das interações entre os sujeitos, na troca de experiências e na reflexão da prática.

A qualificação dos sistemas de ensino e de outros ambientes profissionais se refere à melhoria do trabalho dos professores e de outros profissionais.

Adicionalmente, inserir nas pesquisas questões que emergem da escola contribui para aprofundar soluções para problemas pedagógicos, sendo demonstrados, por exemplo, nos produtos finais desenvolvidos nos mestrados.

A seguir serão apresentados os depoimentos dos coordenadores sobre as contribuições do curso para a formação de professores.

\section{Contribuições para a prática docente}

A fala a seguir revela uma possibilidade formativa interessante quando menciona a produção de materiais didáticos:

[...] ajudar na produção de materiais, saíram coisas diversas, por exemplo, eu orientei uma colega na produção de um livro didático sobre história do município, para ser utilizada por pedagogas e outras pessoas interessadas na história local [...] Também orientei uma outra colega na produção de oficina que tinha por objetivo capacitar os professores a entender, a refletir, a considerar a questão da história de cultura afro-brasileira, mas também fizeram jogos pedagógicos, também análise de vídeos de História do YouTube, são propostas absurdamente diversas, que, se por um lado nos assustaram um pouco, por outro lado, ampliaram o horizonte do professor do que pode ser um trabalho de mestrado em ensino de História. Eu acho que é muito produtiva, muito rica, diversa essa produção que tem sido realizada. Inclusive, a partir desse ano, nós estaremos no prêmio nacional de trabalhos produzidos pelo PROFHISTORIA. (C3).

Percebe-se que a prática de oficinas para elaboração de recursos didáticos é uma experiência exitosa na formação, principalmente quando vinculada às especificidades do curso e à realidade da escola.

No que concerne à reflexão da prática, os coordenadores socializaram que a aprendizagem docente se dá pelas reflexões sobre as ações pedagógicas que desenvolvem na escola e, com essa formação, os docentes se apropriam de novas metodologias que ajudam a efetivar a transposição didática. ${ }^{3}$

A gente aprende também, eu acho que a contribuição maior para além do desenvolvimento do produto é qualificar o quadro dos professores. Nós esperamos, com o PROFHISTÓRIA, qualificar a formação teórico-metodológica-pedagógica desses colegas, e que essa qualificação se estenda para o trabalho que eles realizam na escola. E é muito visível [...], comentam isso, que com o curso eles passaram a refletir de uma outra maneira sobre a prática que vivenciam até então; isso que é de fato a grande contribuição que o curso oferece, que é a reflexão do trabalho. (C3).

Em relação às contribuições do mestrado para a formação docente da educação básica [...],

3 "Um conteúdo de saber que tenha sido definido como saber a ensinar, sofre, a partir de então, um conjunto de transformações adaptativas que irão torná-lo apto a ocupar um lugar entre os objetos de ensino. 0 'trabalho' que faz de um objeto de saber a ensinar, um objeto de ensino, é chamado de transposição didática." (CHEVALLARD, 1991, grifo do autor). 
pela conversa que a gente tem tido e o que eles informam e apontam é que realmente o mestrado está contribuindo não só para uma reflexão sobre seu próprio fazer docente no sentido de aperfeiçoamento, como também está dando segurança para eles ousarem com mais novas metodologias, novas tecnologias aplicadas à sala de aula. Eles estão se sentindo mais seguros nesse aspecto, por desenvolverem a cada semestre esses projetos em que estão tentando fazer a transposição didática o tempo inteiro. (C8).

Os relatos evidenciam a relevância do mestrado, estimulando os estudantes-professores a olharem de forma diferenciada para suas ações pedagógicas, na busca de reconstruí-las por meio dos referenciais teóricos e práticos sobre os quais são feitas as discussões na formação.

Outro aspecto destacado pelos participantes foi a qualificação da prática e da formação:

É a qualificação do professor [...] os professores não voltam do mesmo jeito para a sala de aula, alguns deles se afastaram um pouco da academia. [...] Então o PROFLETRAS foi a chance de muita gente que tinha uma vocação para relacionar pesquisa e ensino pudesse desenvolver isso. Acho que a qualificação do professor é o maior mérito, que isso é uma coisa que, talvez, com os anos traga mais reflexos [...]. (C4.)

As contribuições para a educação básica, de fato isso acontece na prática, a gente incrementar mesmo a formação de professores. Tem, por exemplo, geometria, tem disciplina específica de geometria que ajuda muito quando a gente vai explicar os tópicos lá, justificar o que acontece; eles ficam encantados, alguns não conheciam, dizem que vão levar para sala de aula, isso é bem bacana, disciplina, teorias dos números, aquela parte que fala do mmc, mdc, divisibilidade, também coisas que eles não conhecem, justificativas que podem ser apresentadas aos alunos da educação básica.[...] Minha aluna que defendeu falou sobre criptografia RSA, aquela história da codificação e da codificação em mensagens; ela disse que aplicou na sala de aula e foi super proveitoso, os meninos ficaram empolgados, curiosos. Imagina esses meninos replicarem, chegarem em casa falando que aprenderam sobre segurança de dados, que a mãe não precisa ter mais medo de usar o telefone pra fazer transações, ela não vai precisar ir ao banco, enfim, eu acho que a principal contribuição é isso aí, replicar essas coisas que eles estão vendo, essas novidades que eles estão aprendendo na educação básica. (C7).

É inegável que há interferências significativas no processo de aprendizagem docente, pela maneira como o professor articula a pesquisa e o ensino; relaciona a academia e o campo profissional; integra os conteúdos sistematizados com os saberes do cotidiano dos alunos, atribuindo sentido a eles. Lima (2007, p. 35) alerta que "[...] somente as situações que, de modo específico, problematizam o conhecimento, levam à aprendizagem. Não é qualquer proposta ou qualquer interação em sala de aula, portanto, que promove a aprendizagem".

As práticas de metodologias diferenciadas na sala de aula aparecem como outra contribuição do mestrado, explicitadas quando visam a

Possibilitar que os professores usem em sua prática profissional recursos, estratégias; que se atualizem, se reciclem, tragam oxigenação à sala de aula como fruto do processo de formação continuada. (C6).

[...] desenvolver estratégias a partir desses trabalhos, estratégias de ensino, mas, enfim, alguns temas, eu vi os alunos, temas de dissertação por aí afora, às vezes ficava um pouco difícil, mas só em ter esse contato com a Matemática diferente da que é ensinada em sala de aula, saber que a Matemática se aplica a alguma coisa prática, acho que já é um bom incentivo para os alunos da educação básica. Eu vejo queixa de muitos professores em dizer em que se aplica aquilo, qual a aplicação, 'eu vou usar isso pra que na minha vida', e quando essas dissertações chegam na escola mostrando que a Matemática serve, se aplica na vida, no cotidiano, isso, assim, é louvável. (C7).

Tem lugar nos depoimentos a importância das estratégias de ensino como dispositivos que ajudam na aprendizagem e a melhorar a prática pedagógica. Por outro lado, pode-se correr o risco de delegar às metodologias a única maneira de garantir a qualidade do ensino, ou revelar uma visão pragmatista da formação quando, por exemplo, impõe-se a visão da necessidade de aplicação do conteúdo no cotidiano. É necessário romper com essa concepção da 
"aplicabilidade técnica do conceito", ampliando o pensamento sobre a relação dinâmica entre metodologias, conteúdos e saberes escolares.

Os depoimentos expressam ainda a melhoria da autoestima docente, bem como a valorização profissional, conforme narrado a seguir:

Tivemos um trabalho de um coral chamado Filos [...] pesquisou esse grupo, um coral que tem nessa escola, é professor de artes e formado em música e os regentes, nenhum é da área de música, que ele pesquisou nessa escola. Muito interessante porque tem muita gente que não é da música, que não é artes e desenvolve um trabalho ligado à música, ligado a artes, estou lembrando desse trabalho. [...] Teve outro trabalho, é com percussão, as apresentações com muitos vídeos, fotos, um trabalho bem escrito [...] Outro trabalho lá de uma professora que tinha um problema sério, passa uma linha de trem por trás da escola e passava com frequência, exatamente na hora da aula dela; toda aula passava e era muito difícil dar aula nesse horário, e ela incorporou o trem à aula de música. Passou a usar aquela sonoridade nas aulas de música, também foi um trabalho interessante... Mas tem implicações, sim, diretamente na escola, implicações efetivas na experiência de pesquisa, tem um efeito colateral bom, positivo, digamos assim, que é a valorização desse profissional dentro da escola, a autoestima desse profissional melhora muito, justamente por conta desse reconhecimento [...] 0 nosso resultado tem sido muito bom na qualidade dos trabalhos e nas implicações que isso tem para a escola e para o professor, e também para os estudantes da escola, porque eu tenho um professor ali estimulado com a sua área, capacitado, pensando, refletindo sobre a sua área. [...] têm contribuições relevantes em todas essas dimensões que eu falei, na autoestima do professor, na motivação do professor, em pensar a própria área, e isso com certeza chega ao estudante, e o reconhecimento e a valorização perante os pares dentro da escola, perante a direção, a coordenação da escola, é um reconhecimento e uma valorização também importante que se obtém através do mestrado profissional em Artes. (C5).

A análise do fragmento aponta alguns aspectos tais como: o envolvimento dos estudantes-professores com as atividades propostas; a busca de alternativas para trabalhar a área do conhecimento; valorização dos condicionantes sociais da comunidade educativa na inserção do planejamento pedagógico; a mobilização do espaço escolar por meio de intervenções na prática docente; e, como resultado desses elementos, a valorização do trabalho docente e um sentimento de pertencimento dos sujeitos envolvidos, associado à melhoria da autoestima.

A última contribuição apontada é a aproximação da universidade com a escola e da escola com a universidade, conforme manifesta o coordenador:

Eles têm dado uma contribuição muito relevante por causa desses fatores, diminuir a distância entre a universidade e a escola, porque aquele professor que sai da universidade, aquele discurso que chega na escola e na prática, a teoria é diferente, que se fala muito isso, e o mestrado profissional ajuda a superar essa dicotomia, até porque o mestrado tem a ver com o fazer docente desse professor na escola, está ligado com o que ele faz na escola. (C5).

Constata-se que a integração dessas duas instituições se torna um aprendizado para os professores que trabalham no mestrado e para os estudantes-professores. No primeiro caso, pelo contato com os fenômenos oriundos da prática escolar, o que possibilita entender mais profundamente as situações do contexto escolar e da sala de aula, o que leva os formadores a rever concepções e metodologias dos cursos de licenciatura. No segundo caso, os estudantes-professores têm oportunidade de relacionar teoria e prática, investigar a prática pedagógica, para intervenção na sua realidade. Nesse enfoque, Nóvoa (2017b, p. 1117) chama atenção: "Não se trata, apenas, de levar a universidade às escolas ou de trazer as escolas até a universidade, mas sim de construir um novo lugar, em conjunto, em colaboração, valorizando os conhecimentos e as experiências de todos.",

\section{Conclusão}

Com base no que foi delineado no texto, concluímos que o mestrado profissional em rede, mesmo com suas limitações, é expresso como um caminho para a qualidade 
da formação de professores em busca de uma aprendizagem docente que reverberará em transformações possíveis na prática pedagógica, em termos das ações e relações vivenciadas na sala de aula. Tal propositiva, possivelmente, se constitui elemento favorável à melhoria da escola básica.

Os resultados da investigação mostraram que há nos mestrados profissionais em rede a centralidade na formação de professores da educação básica, numa perspectiva de desenvolvimento profissional, por propiciar a reflexão das práticas pedagógicas e novas formas de intervenção no contexto escolar.

Evidenciaram-se os seguintes desafios: o reconhecimento da universidade quanto à relevância do mestrado profissional para professores; melhorar as formas de ensinar e pesquisar no curso; potencializar a dimensão macro nas intervenções dos estudantes, deixando de ser um atividade pontual na formação; trabalhar para a melhoria da reflexão pedagógica sobre o ensino; contemplar as demandas formativas, inserindo conteúdos do contexto escolar na formação; desenvolver a concepção de rede com base na unidade e na colaboração, valorizando a autonomia das universidades; e garantir implicações na educação básica com a melhoria da qualidade do ensino.

As contribuições retratadas no estudo apontaram para a importância desses mestrados, destacando-os como espaços de produção de materiais didáticos, articulados às especificidades do curso e da escola, e por promover práticas reflexivas, ajudando os estudantes -professores na apropriação de novos conceitos e novas metodologias. Essa reflexão da prática proporciona uma transformação da ação pedagógica, com implicação direta na aprendizagem do aluno da escola.

Articular pesquisa e ensino, integrar o campo acadêmico com o profissional, ajudar a sistematizar e ampliar os saberes da escola e desenvolver metodologias diferenciadas são ações concretas que testemunham o mérito do mestrado para a aprendizagem docente.
Outro aspecto evidenciado foi a melhoria da autoestima docente, com o reconhecimento da escola pelo trabalho empreendido pelos estudantes-professores. Ficou evidente que o contato direto da escola com a universidade e vice-versa possibilita oportunidade de formação aos envolvidos, uma vez que os ajuda a compreender mais profundamente as situações do campo escolar e a mobilizar novos conhecimentos profissionais e acadêmicos.

Concluindo, os dados revelam um campo fértil de debate acerca da formação de professores da educação básica pública e a necessidade de outras pesquisas que expressem a prática e a importância dos mestrados profissionais no Brasil.

\section{REFERÊNCIAS}

ANDRÉ, Marli Eliza Dalmazo Afonso de. Texto, contexto e significado: algumas questões na análise de dados qualitativos. Cadernos de Pesquisa, São Paulo, n. 45, p. 66-71, maio 1983. Disponível em: http://publicacoes.fcc.org.br/ojs/index.php/cp/ article/view/1491. Acesso em: 09 out. 2019.

ANDRÉ, Marli Eliza Dalmazo Afonso de. Mestrado profissional e mestrado acadêmico: aproximações e diferenças. Revista Diálogo Educacional, Curitiba, v. 17, n. 53, p. 823-841, 2017. Disponível em: https:// periodicos.pucpr.br/index.php/dialogoeducacional/ article/view/8459. Acesso em: 09 out. 2019.

BRASIL. Ministério da Educação. Portaria Normativa no 17, de 28 de dezembro de 2009. Dispõe sobre o mestrado profissional no âmbito da Fundação Coordenação de Aperfeiçoamento de Pessoal de Nível Superior - CAPES. Diário Oficial da União: seção 1, Brasília, DF, n. 248, p. 20, 29 dez. 2009.

CALDATTO, Marlova Estela. o PROFMAT e a formação do professor de Matemática: uma análise curricular a partir de uma perspectiva processual e descentralizadora. 2015. Tese (Doutorado em Educação para a Ciência e o Ensino de Matemática) - Programa de Pós-Graduação em Educação para a Ciência e a Matemática da Universidade Estadual de Maringá (UEM), Maringá, PR, 2015.

COORDENAÇÃO DE APERFEIÇOAMENTO DE PESSOAL DE NÍVEL SUPERIOR (Capes). Plataforma Sucupira, 2017. Disponível em: https://sucupira. capes.gov.br/sucupira/. Acesso em: 10 ago. 2019.

CHEVALLARD, Yves. La transposition didactique: du savoir savant au savoir enseigné. Paris: La 
Pensee Sauvage, 1991.

DAY, Christopher. Desenvolvimento profissional de professores: os desafios da aprendizagem permanente. Porto: Porto Editora, 2001.

DOURADO, Luiz Fernandes. Diretrizes curriculares nacionais para a formação inicial e continuada dos profissionais do magistério da educação básica: concepções e desafios. Revista Educação \& Sociedade, Campinas, SP, v. 36, n. 131, p. 299-324, abr./ jun. 2015. Disponível em: http://www.scielo.br/ scielo.php?pid=S010173302015000200299\&scri pt=sci_abstract\&tlng=pt. Acesso em: 09 out. 2019. FIALHO, Nádia Hage; HETKOWSKI, Tânia Maria. Mestrados profissionais em educação: novas perspectivas da pós-graduação no cenário brasileiro. Educar em Revista, Curitiba, n. 63, p. 19-34, jan./ mar. 2017. Disponível em: http://www.scielo.br/ scielo.php?pid=S010440602017000100019\&scri pt=sci_abstract\&tlng=pt. Acesso em: 09 out. 2019.

FIORENTINI, Dario. A pesquisa e as práticas de formação de professores de Matemática em face das políticas públicas no Brasil. Bolema, n. 29, p. 4370, 2008. Disponível em: https://www.periodicos. rc.biblioteca.unesp.br/index.php/bolema/article/ view/1718. Acesso em: 09 out. 2019.

FURLAN, Michel; HARGREAVES, Andy. A escola como organização aprendente: buscando uma educação de qualidade. Porto Alegre: Artes Médicas, 2000.

GARCIA, Carlos Marcelo. Formação de professores. Para uma mudança educativa. Porto: Porto Editora, 1999.

IMBERNÓN, Francisco. Formação docente e profissional: formar-se para a mudança e a incerteza. 6. ed. São Paulo: Cortez, 2006.

KINCHELOE, Joe L. A formação do professor como compromisso político: mapeando o pós-moderno. Porto Alegre: Artes Médicas, 1997.

KUENZER, Acacia Zeneida. As políticas de formação: a construção da identidade do professor sobrante. Educação \& Sociedade, Campinas, SP, v. 20, n. 68, p. 163-183, dez. 1999. Disponível em: http://www.scielo. br/scielo.php?pid=S010173301999000300009\&sc ript=sci_abstract\&tlng=pt. Acesso em: 09 out. 2019.

LIMA, Elvira Souza. Currículo e desenvolvimento humano. Indagações sobre currículo: currículo e desenvolvimento humano. Brasília, DF: Ministério da Educação/Secretaria de Educação Básica, 2007.
LÜDKE, Menga; ANDRÉ, Marli Eliza Dalmazo Afonso de. Pesquisa em educação: abordagens qualitativas. São Paulo: EPU, 1986.

MIZUKAMI, Maria da Graça Nicoletti. Escola e desenvolvimento profissional da docência. In: GATTI, Bernardete A. et al (org.). Por uma política nacional de formação de professores. São Paulo: Unesp, 2013. p. 23-40.

MOREIRA, Marco Antonio. O mestrado (profissional) em ensino. Revista Brasileira de Pós-Graduação, Brasília, DF, ano 1, n. 1, p. 131-142, jul. 2004.

NÓVOA, Antônio (coord.). Os professores e a sua formação. 2. ed. Lisboa: Dom Quixote, 2017a.

NÓVOA, Antônio. Firmar a posição como professor, afirmar a profissão docente. Cadernos de Pesquisa, v. 47, n. 166, p. 1106-1133, 2017b. Disponível em: http://www.scielo.br/scielo.php?pid=S01001 5742017000401106\&script=sci_abstract\&tlng=pt. Acesso em: 09 out. 2019.

REZENDE, Flavia; OSTERMANN, Fernanda. 0 protagonismo controverso dos mestrados profissionais em ensino de ciências. Ciência \& Educação, Bauru, SP, v. 21, n. 3, p. 543-558, 2015. Disponível em: http://www.scielo.br/scielo. php?script=sci_abstract\&pid $=$ S15167313201500 $0300002 \& \operatorname{lng}=$ en\&nrm=iso\&tlng=pt. Acesso em: 09 out. 2019.

RODRIGUES, Ângela. Análise de práticas e de necessidades de formação. Ministério da Educação/ Direção Geral de Inovação e de Desenvolvimento Curricular. Lisboa: Edições Colibri, 2006.

RODRIGUES, Ângela. Contributo para o estudo das necessidades de formação dos professores do ensino secundário. 1991. Dissertação (Mestrado em Ciências da Educação) -Faculdade de Psicologias e Ciências da Educação, Universidade de Lisboa, 1991.

ZEICHNER, Kenneth. M. A formação reflexiva de professores: ideias e práticas. Lisboa: Educa, 1993.

ZEICHNER, Kenneth. M. Repensando as conexões entre a formação na universidade e as experiências de campo na formação de professores em faculdades e universidades. Educação, Santa Maria, RS, v. 35, n. 3, p. 479-504, set./dez., 2010. Disponível em: https://periodicos.ufsm.br/reveducacao/article/ view/2357. Acesso em: 09 out. 2019.

Recebido em: 12/10/2019 Aprovado em: 10/02/2020 